\title{
ALOÍSIO SURGIK. VIAJANDO PELA HISTÓRIA. DO DIREITO ROMANO AO DIREITO CONTEMPORÂNEO.
}

\author{
Curitiba (PR): I. SCHERER, 2010, 346 p.
}

\begin{abstract}
Ramón Rodríguez Montero
Professor titular de Direito Romano (Universidade da Coruña, Espanha) www.ramonprodriguezmontero.es
\end{abstract}

A finales del pasado mes de marzo, durante mi asistencia al Congreso que la Asociación Internacional de Derecho romano (AIDROM) viene celebrando anualmente -el presente lo fue en la Universidad de Almería-, el profesor brasileño Aloísio Surgik, asiduo participante desde hace muchos años en los Congresos de la mencionada Asociación, me entregó su último libro, recientemente publicado, titulado "Viajando pela História. Do Direito romano ao Direito contemporáneo", acompañado de una amable e inmerecida dedicatoria.

Aún cuando ya en aquél momento tuve la ocasión de agradecerle su deferencia, manifestándole la ilusión que desde siempre me produce recibir libros, y más especialmente cuando los mismos se encuentran dedicados, transcurridos unos meses, tras realizar la correspondiente lectura de la obra, me permito en estas breves notas dar cuenta de la misma, en testimonio de amistad y reiterado agradecimiento hacia su autor.

El libro del prof. Surgik contiene, ordenadas cronológicamente, once comunicaciones presentadas y discutidas en diversos Congresos internacionales de Derecho romano, celebrados a lo largo de diversos años, así como una contribución aportada al libro "Humanismo e Cultura Jurídica no Brasil”, coordinado por Antônio Carlos Wolkmer (Fundação Boiteaux, Florianópolis, 2003). Intercaladas entre el texto aparecen también diversas fotografías que recogen momentos de las intervenciones del autor en algunos de los citados Congresos. Completa el volumen un elenco de referencias bibliográficas relacionadas con los temas tratados en el mismo.

Los trabajos que integran la publicación "forman parte de la Historia del Derecho, y particularmente del Derecho romano, sobre todo considerándose el sentido romano de la cosa pública, frente a la reciente política de las privatizaciones, tema éste que permea las consideraciones críticas y constituye la tónica general de la presente obra en su conjunto". De esta forma, aún cuando en su obra se contengan temas diversos, el hilo conductor de los mismos, con el que se pretende "conferirles cierta unidad, o por lo menos la intención de focalizar puntos fundamentales", es el "tema de las privatizaciones".

Los dos primeros trabajos, titulados respectivamente "Da violação da liberdade na cobrança de pedágio" y "A luta pela propiedade da terra na história de Roma e no Brasil" - de los que el autor confiesa haber dudado en un primer momento sobre su inclusión en la obra, por encontrarse ya disponibles en internet- tratan de problemas de evidente interés actual, siendo todavía objeto de debate, sin que, por lo demás, todavía se hayan resuelto.

Por lo que se refiere al primero, en relación al cobro de peajes en las autovías y vías públicas -que está siendo cuestionado en el momento actual en algunos países de la Unión 
Europea, como por ejemplo es el caso de España o Portugal-, el prof. Surgik considera que, tanto las citadas autovías como las vías públicas, "no pueden ser objeto de concesión para explotación de peaje, aún con promesas de mejora de su calidad, porque su construcción, manutención y conservación en buenas condiciones es de entera responsabilidad del poder público, que ya recauda tributos para esta finalidad, debiéndole garantizar a cada ciudadano el derecho a desplazarse con plena seguridad", subvirtiéndose en caso contrario el que califica como "orden de valores", y "constituyendo una ofensa al ciudadano en su condición humana como ser libre". En este sentido, según el autor, "las autovías y vías públicas, por su propia naturaleza, en cuanto pertenecientes al pueblo, entran en la categoría de las res extracommercium (cosas públicas, desde la más remota tradición romana), no pudiendo, por tanto, ser explotadas comercialmente, ni siquiera a través del cobro de peaje, bajo disfraz de "precio público". A su entender, "solamente el poder público tiene competencia para cobrar tributos, instituidos regularmente por ley y mediante actividad administrativa plenamente vinculada"; "el cobro indebido sobre aquello que ya nos pertenece en nuestra condición de ciudadanos forma parte de la lógica perversa en que el interés público se pospone en provecho del interés privado y del gran capital, en un verdadero comercio de la cosa pública, bajo pretexto de aparcería público-privada, pero que, en realidad, es "privacidad" público-privada".

En “A luta pela propiedade da terra na história de Roma e no Brasil”, el autor se ocupa de los graves problemas relacionados con la disputa por la posesión y la propiedad de la tierra en Brasil, especialmente desde un punto de vista histórico-crítico.

A partir del paralelo que establece entre la que califica como "desgracia" que tuvo el proyecto de reforma agraria de los hermanos Gracos, cuyo final, como es sabido, fue trágico, y las numerosas muertes que viene provocando la lucha por la reforma agraria en el Brasil actual, el prof. Surgik señala que "resulta forzoso reconocer que hoy estamos sufriendo un lamentable retroceso", y que "el ejemplo del pasado debe estimularnos en el presente".

Destaca dos aspectos sobre los que realiza diversas consideraciones críticas: por una parte, el tratamiento jurídico desigual que se viene dispensando por parte de las autoridades públicas a los ocupantes de "tierras ociosas", que, frente a los grandes propietarios latifundistas, no disponen de mecanismos procesales adecuados que los amparen en la búsqueda de sus derechos fundamentales, que concreta en el derecho a la reforma agraria, al trabajo, a una vivienda digna y, sobre todo, a la obtención de alimentos para sí y para sus hijos; por otra, el uso de un vocabulario que califica como "manifiestamente tendencioso" -empleo sistemático de la palabra "invasión" y su respectivo verbo "invadir", en vez de otros, como por ejemplo, "ocupar"-, utilizado por los grandes medios de comunicación, denigrando la imagen de los "sin tierra" ante la opinión pública, y predisponiendo a la misma para considerarlos como delincuentes.

"As presunções como meios de prova (de Roma á atualidade)" es el título de la tercera de las contribuciones que el prof. Surgik incluye en su obra. En la misma se ocupa de estudiar desde el punto de vista histórico la que califica como axiomática estrecha vinculación que algunos juristas establecen entre las nociones de "presunción” y "prueba”, no sólo exclusivamente para las llamadas presunciones "judiciales" o "simples" (praesumptiones hominis), sino también para las presunciones legales "absolutas" (iuris et de iure) y las relativas (iuris tantum).

El prof. Surgik analiza la relación que se establece entre las presunciones y las pruebas en las fuentes romanas, en el Fuero Juzgo, en el libro Flores de las Leyes, en el libro de las Siete Partidas, en el antiguo Derecho lusitano (Libro de Leyes y Posturas, Ordenaciones Alfonsinas, Manuelinas y Filipinas), en el Derecho canónico -en el que resalta su especial importancia, indicando al respecto que "las presunciones en cuanto vinculadas a las pruebas, en 
verdad, crecieron, se ramificaron y se multiplicaron en su terreno más fértil, que fue el Derecho canónico"- y en el Derecho procesal civil brasileño, para finalizar refiriéndose a la diferenciación entre presunción y ficción.

El cuarto trabajo, que lleva por título "Da necessidade da boa-fé objetiva na ética proffisional do advogado", pretende, en palabras del autor, "focalizar inicialmente la fides en un análisis más amplio sobre el punto de vista jurídico romano, restringiendo a continuación el tema al sector específicamente relacionado con la ética profesional del abogado, considerando que, aun a pesar de los siglos transcurridos, la buena fe (referente de la conducta del pueblo romano en sus relaciones jurídicas, sociales, comerciales y familiares, entre otras) todavía se constituye en una verdadera fuente de lecciones para los operadores del Derecho".

Destaca el prof. Surgik en esta contribución que, en el Código civil brasileño que se encontraba en vigor en el momento de escribir su comunicación, presentada en el año 2001 -y que, como advierte en el Prólogo de su libro, con el transcurso de los años sería sustituido en el 2003 por otro, actualmente vigente, que consagró el principio de la buena fe objetiva-, la gran mayoría de los artículos que se referían a la buena fe tenían una connotación nítidamente subjetiva, lo que, a su entender, por la facilidad de simulación, dificultaba poder escrutar la conciencia humana e inviabilizaba hasta cierto punto la propia concretización de la justicia.

Precisamente, el gran avance de la legislación brasileña en relación al acogimiento de la buena fe objetiva se verificó, según el autor, al regular los derechos del consumidor mediante la Ley $\mathrm{n}^{\mathrm{0}} 8.078 / 90$, en la que se contempló - sin perjuicio de que hasta entonces se viniese reconociendo doctrinal y jurisprudencialmente- en forma de cláusula general dicho principio de la buena fe objetiva. Por lo que se refiere al ámbito del proceso civil brasileño, en opinión del prof. Surgik, si se examina el Código de Proceso Civil brasileño, se puede verificar que el principio de la buena fe objetiva realmente se mantiene, inclusive respecto a los abogados, y que el mismo regula minuciosamente en su artículo 15 la conducta del abogado; pero que, sin embargo, la Ley 8.096/94, que regula específicamente la ética del abogado, se muestra en sentido diverso del mencionado Código, puesto que en ella se inclina el principio de la buena fe del campo objetivo hacia el subjetivo. Finalmente, el autor hace hincapié en su artículo en la responsabilidad del abogado ante la sociedad, recalcando la necesidad de la buena fe objetiva en su ética profesional.

En “A quaestão da responsabilidade civil do Estado perante o Direito romano", el prof. Surgik realiza diversas reflexiones críticas sobre la consideración del Estado como persona jurídica.

Partiendo de las fuentes romanas, especialmente en lo relativo al binomio derecho público y derecho privado -cuya distinción, según su criterio, debe de pasar por una profunda revisión crítica en atención a las interpolaciones del texto D. 1.1.1.2, atribuido a Ulpiano, así como a la absoluta imposibilidad en Derecho romano de asociar al derecho público la idea de Estado-, entiende que no existió en Roma el Estado como persona jurídica, considerando, por tanto, absolutamente anacrónica e inadecuada la expresión "Estado romano". A su entender, resulta inadmisible suponer que entre los romanos hubiese existido una persona jurídica separada de la persona física, porque, lejos de imaginarse que aquellos fuesen incapaces de realizar una abstracción, lo que en verdad no admitían era exonerar a la persona física, diluyendo su responsabilidad en una entidad abstracta como es la persona jurídica.

Según el prof. Surgik, la persona jurídica, en cuanto que separada de la persona física, lejos de poder explicarse científicamente, es más fácilmente explicable como fenómeno histórico. Encuentra su origen estrechamente ligado a las entidades religiosas del Bajo Imperio romano. Las personae fictae, como punto de constitución definitiva de la persona jurídica y, consecuentemente, del Estado, tuvieron su origen en el Derecho canónico, y no en el Derecho romano. Para el autor, 
lamentablemente, al estudiar a la persona jurídica, la llamada Ciencia jurídica moderna, más preocupada en explicar su naturaleza jurídica, no siempre ha demostrado el mismo empeño en investigarla como instrumento de fraude. En su opinión, el Estado debe someterse a un riguroso análisis crítico en cuanto a su papel en relación a la responsabilidad civil, teniendo en cuenta la que califica como "inaceptable sumisión a poderosos grupos económicos, que viene acarreando graves consecuencias en la subversión del Derecho y, por tanto, en la violación de la Justicia".

La sexta de las contribuciones que se recoge en el libro, que fue objeto de la comunicación presentada en el mes de agosto del año 2001 durante el XIII Congreso Latinoamericano de Derecho romano, celebrado en la Universidad de La Habana, lleva por título "O Direito romano perante a tragédia da Globalização", sirve al prof. Surgik para analizar la que califica como "grave crisis" que "envuelve no sólo al mundo jurídico, sino también a los más variados sectores de la vida política, económica, social", "la gran crisis de valores que se amplía en acelerado proceso de exclusión social, haciendo que millones de personas se vean en la contingencia de sobrevivir en la más dramática miseria, por debajo de los límites de la propia dignidad humana”.

En su opinión, gran parte del mundo sufre las que califica como "consecuencias desastrosas del ideario neo-liberal", indicando que sus objetivos van desde "la destrucción del Estado nacional, en la medida en que dificulte la integración a la lógica de la globalización financiera y especulativa, hasta la masacre de los movimientos de resistencia política de aquellos que se oponen a los designios del mercado, que se pretende imponer como divinidad suprema". Según el prof. Surgik, "las falsas esperanzas que el sistema de mercado viene imponiendo al mundo contemporáneo exigen ciertamente un arduo combate por una cultura jurídica basada en sólidos principios de solidaridad y fraternidad contra la cultura capitalista del egoísmo individualista y de la muerte". A su entender, "resulta necesario asimilar las lecciones históricas del Derecho romano, que se expandió universalmente no tanto por su carácter imperialista cuanto, sobre todo, por su valor cultural, imbuido de profundo sentido ético, basado en los más sólidos fundamentos de la bona fides", concluyendo que "frente a la gran prensa y a la televisión, que se encuentran en manos de la minoría dominante, resulta posible resistir, no sólo mediante el combate por la democratización de los medios de comunicación, sino también mediante la construcción de una red cultural alternativa, a partir de los sindicatos, de las comunidades de base, de los movimientos campesinos e indígenas, de las Asociaciones de barrio, etc., con la posibilidad de crear un Derecho popular, a semejanza del Derecho romano en su mejor expresión clásica”.

"Da fiducia cum creditore ao contrato de alienação fiduciaria em garantía" es el séptimo trabajo que aporta en su libro el romanista brasileño.

En el mismo, el prof. Surgik contrapone la antigua institución romana de la fiducia cum creditote a la más cercana en el tiempo enajenación fiduciaria en garantía introducida en Brasil por influencia del mercado de valores a través del Decreto Ley $n^{\circ} .911 / 69$, resaltando, además del profundo deterioro sufrido por la primera en su sentido originario a lo largo de los siglos, la inspiración de la segunda en la figura anglosajona del trust receipt. A su entender, uno de los aspectos más críticos del mencionado Decreto Ley es la introducción en el proceso civil brasileño, de rito sumarísimo y defensa limitada, autorizando al acreedor, en proceso autónomo e independiente, acción de busca y aprehensión y acción de depósito contra el deudor, con las consiguientes responsabilidades penales, que considera inaceptables teniendo en cuenta los principios del Derecho penal. Según el prof. Surgik, la enajenación fiduciaria en garantía, que fue incorporada en el nuevo Código civil brasileño del año 2003, al dedicarse en el mismo un capítulo especial a la propiedad fiduciaria, también ha suscitado muchas polémicas en los Tribunales brasileños. En su opinión, por los motivos expuestos, se debería "extirpar tal figura de la legislación brasileña". 
En el octavo de los trabajos, titulado "Humanismo e cultura jurídica na obra de Teixeira de Freitas", el autor, tras examinar brevemente el Humanismo dentro de la historia de las ideas, se ocupa de analizar algunos aspectos que califica como "particularmente interesantes", relativos al humanismo y a la cultura jurídica dentro de la obra del gran jurista brasileño del siglo XIX, Augusto Teixeira de Freitas.

Según el prof. Surgik, el humanismo de Teixeira de Freitas se caracteriza principalmente por la defensa intransigente de la libertad humana. Al encontrarse su formación jurídica sólidamente asentada en el Derecho romano, ello le permitió cultivar un "humanismo científico". A pesar de las tendencias positivistas adversas de su época, en su opinión, resulta "particularmente admirable" el hecho de que Teixeira de Freitas haya tenido una vivencia humana, y que nos la haya transmitido.

"A manus e o consensus no casamento romano" se corresponde con la comunicación presentada en el VI Congreso Internacional y IX Iberoamericano de Derecho romano, celebrado en el mes de febrero de 2003 en la Universidad de Huelva.

El prof. Surgik señala en este trabajo algunos puntos que, en su opinión, "podrían indicar nuevas líneas de investigación y análisis crítico" en relación al matrimonio.

A su entender, considera que se podría cuestionar hasta qué punto las legislaciones relativas al matrimonio (y al Derecho de familia en general) de los países que se mantuvieron predominantemente católicos, y en los que todavía permanecen generalmente lazos muy estrechos entre la Iglesia y el Estado, no serían hoy más que un repositorio de preceptos religiosos antes que jurídicos. En segundo lugar, también piensa que se debería cuestionar la existencia de los llamados "derechos indisponibles", en cuya categoría se alinea, entre otros, el Derecho de familia, considerando que la citada expresión, en sí misma, ya es contradictoria, puesto que, en su opinión, "un derecho del que no se puede disponer, deja de ser derecho". Finalmente, observa que “considerándose que son innumerables los deberes impuestos sobre la máscara de los derechos, cabe investigar por qué el Derecho de familia ha sido creado no tanto para atribuir derechos, cuanto para imponer deberes", concluyendo que "el Derecho no puede ser concebido como fuerza de dominación, sino como instrumento de liberación".

En el décimo escrito, titulado "O povo romano e o julgamento de Catilina (Reflexões críticas sobre os textos de Cícero e de Salústio)" el autor, tomando como base las "Catilinarias" -“In Catilinam oraciones quator"- de Cicerón, y la obra de Salustio -"De coniuratione Catilinae"-, pretende "rescatar, en la medida de lo posible, a través de una relectura crítica de los mismos, la verdadera imagen de Catilina y de Cicerón, así como los motivos que habrían impulsado a ambos para adoptar las actitudes que adoptaron".

Tratando sucintamente de algunos aspectos biográficos de Cicerón, Salustio y Catilina, el prof. Surgik señala respecto al primero que la vida de Cicerón fue muy turbulenta, a pesar de lo cual, y a diferencia de lo que sucedió a los otros autores de la Antigüedad dejó una vasta producción literaria, quizá por el hecho de que los copistas medievales, en su mayoría eclesiásticos, fueron especialmente complacientes en la preservación de sus obras, al coincidir en gran medida con las bases doctrinales del cristianismo. Por lo que se refiere al historiador Salustio, fervoroso admirador y seguidor de César, al escribir su conocida obra "De coniuratione Catilinae", según el prof. Surgik, lo hizo fundamentalmente con el deseo de librar a César de la tacha de complicidad con Catilina, razón por la cual su texto debe ser leído con muchas reservas. Finalmente, el prof. Surgik, considera que la figura de Catilina ha sido excesivamente deformada por la Historiografía y la Literatura. Sin embargo, aunque realmente hubiese cometido todos los crímenes que le fueron imputados en las Catilinarias de Cicerón, éste jamás podría condenarlo en 
la forma en que lo hizo, puesto que, más allá de la inexistencia de pruebas, solamente al pueblo cabría juzgar casos como el de la naturaleza de Catilina, es decir, en la Asamblea debidamente convocada y, en todo caso, a través de la provocatio ad populum.

En opinión del prof. Surgik la grave crisis que sufrió la experiencia republicana romana se debió principalmente a la reforma militar llevada a cabo por Cayo Mario, al profesionalizar el servicio militar, pasando a ser de esta forma la guerra un apetecible instrumento de lucro en manos de muchos comandantes y de sus soldados, lo que fue decisivo para provocar la caída de la República. Bajo estas circunstancias, según el autor, Catilina debe ser considerado no como un conspirador, sino más bien como un revolucionario. A su modo de ver fue una de las víctimas de la crisis republicana. Los textos de Cicerón y Salustio, analizados críticamente, pueden, a su entender, por una parte, ayudarnos a rescatar la verdadera imagen de Catilina, y, por otra, a ver a Cicerón no como un símbolo de la defensa de los valores republicanos, sino como uno de los agentes de la instauración del Imperio. Según el autor, Catilina, por su grandeza en defender la justicia social, debe recibir ciertamente la justa y merecida petición de perdón -aun cuando ya han pasado más de dos mil años- por parte de todos aquellos que le condenaron.

“A sucessão testamentaria no Direito romano tardío e seu papel na gênese da pessoa jurídica" es el penúltimo trabajo incluido en el libro objeto de la presente reseña. En el mismo, el prof. Surgik vuelve a ocuparse de la persona jurídica, analizando la práctica testamentaria en el Derecho romano tardío y la que califica como "curiosa ligazón" que se puede establecer a partir de diversos desdoblamientos históricos entre tales testamentos y la génesis de la persona jurídica, al desconocer el Derecho romano clásico tal concepto abstracto de persona jurídica.

Según el autor, especialmente en cuanto se intensificó la práctica de los testamentos a favor de las "causas pías", el testamento, frente a lo que ocurría anteriormente, pasó a asumir un carácter más patrimonial. La necesidad de evitar la disipación de los patrimonios destinados por testamento a esas causas piadosas motivó la creación de nuevas formas de inalienabilidad, a semejanza de lo que había ocurrido anteriormente con las res divini iuris, estableciéndose así los primeros fundamentos de separación entre las personas físicas y las corporaciones religiosas. Posteriormente, en el siglo XIII, con el canonista Sinibaldus Fliscus, surgió la "persona ficta", idealizada por él para separar a las personas físicas -presumiblemente inocentes- del conjunto de los habitantes de una ciudad -"persona ficta"- alcanzada por la pena de excomunión. A continuación, la "persona ficta" abrió el camino para la concepción de la "persona moral", que, a su vez, se transformó por obra de la Pandectística alemana en la actual figura de la persona jurídica, también ficticia.

En opinión del prof. Surgik, de la persona jurídica, enaltecida y difundida como la gran invención de nuestro tiempo, deriva la proliferación de muchas formas de entidades ficticias cuyos fines no siempre atienden a los intereses del bien común, inclusive las sociedades anónimas, que, muchas veces, en complicidad con el Estado (también persona jurídica), constituyen en el contexto de las desigualdades sociales del mundo capitalista una de las principales causas de la crisis del Derecho contemporáneo.

El libro finaliza con el trabajo titulado "Res extracommercium: de Roma aos tempos atuais", en el que el autor fija su atención especialmente sobre el sentido romano de las res extracommercium, extrayendo del mismo algunas consideraciones críticas sobre las graves desfiguraciones sufridas a lo largo de los tiempos, convirtiendo en la actualidad a dichas cosas en verdadera mercancía a causa de un sistema socio-político-económico basado en un proceso que, al margen de ciertos valores y principios éticos indispensables para la convivencia social, como la buena fe, la equidad y la solidaridad, pretende transformar el mundo instituyendo como divinidad suprema al mercado. 
Para el prof. Surgik no se puede aceptar simplemente el argumento de que el servicio público estaría siendo insuficiente y por ello que ciertos sectores del patrimonio público deberían ser vendidos en provecho de la explotación privada, puesto que, por su propia naturaleza y especificidad, hay determinados sectores que jamás pueden ser entregados a la actividad comercial por ser claramente de exclusivo interés colectivo.

En el caso brasileño, según el autor, tratándose de privatizaciones bajo el disfraz de concesiones, como es el supuesto del cobro de peajes en autovías públicas -al que ya se refirió en el primero de los trabajos recogidos en su libro- es evidente que, como mínimo, se debería asegurar al usuario (que ya paga impuestos) el derecho a poder utilizar otra vía alternativa de buena calidad para conducirle, sin gravamen alguno, al destino deseado, lo que generalmente no ocurre en Brasil. Por ello, en opinión del prof. Surgik, es obvio que el cobro de peaje en estas circunstancias no deja de ser sino una forma camuflada de apropiación indebida del espacio público por el sector privado, además de tratarse de una evidente violación del derecho a la libertad, consubstanciado en el derecho natural de ir y venir. Ni la Unión Federal, ni los Estados miembros, ni los Municipios tienen la propiedad de las autovías, que, según el autor, pertenecen al pueblo. De ahí la absoluta inconsistencia, bajo cualquier título, de las privatizaciones en el sector.

A todo lo expuesto, el prof. Surgik añade que la Medida Provisional $n^{0} 155$, que se transformó en la Ley $\mathrm{n}^{\mathrm{o}}$ 8031, de 12 de abril de 1990, promulgada bajo el pretexto de que el Estado debería concentrar su actuación en actividades típicamente públicas, como la educación y la salud entre otras, contiene en sí misma una grave contradicción, al estar siendo objeto del proceso de privatización dichas actividades. Esta "tercerización de servicios esenciales y de las cuentas de la Prefectura" que se está operando en los Municipios brasileños, en palabras del autor, "no es nada más que una demostración clara de la profunda crisis del mundo contemporáneo en la ciega sumisión al mercado, envolviendo incluso mismamente hasta a la educación de primer grado frente al poder público municipal, cuyo papel se vuelve también cada vez más opaco respecto a sus responsabilidades".

A mi juicio el libro reseñado en estas páginas ofrece al lector en los difíciles tiempos por los que atravesamos algunos motivos para realizar una reflexión seria y sincera sobre los acontecimientos que estamos viviendo, o quizá mejor, que nos están haciendo vivir determinados estamentos políticos y económicos desde su posición de poder y en atención a sus propios intereses particulares, manipulando a su antojo a la colectividad. Resulta por ello meritorio que el prof. Surgik, con el compromiso y rebeldía que se trasluce perfectamente a través de su obra, nos haga tomar conciencia de dichas circunstancias.

Sinceramente, desconozco hasta qué punto y en qué medida el Derecho romano de la época republicana pueda ser presentado, según lo hace de forma enaltecida el prof. Surgik a lo largo de su obra, como un posible ejemplo a seguir en los momentos actuales. Y ello, porque no se puede olvidar que el propio sistema jurídico romano republicano, con independencia de los valores, virtudes y bondades que pueda contener en sí y que se puedan abstraer de forma atemporal para ser utilizados en el presente, indudablemente es tributario de los concretos intereses de un grupo social reducido, así como de unas condiciones históricas, políticas y económicas que se dieron en un contexto muy concreto.

En cualquier caso, concuerdo plenamente con el profesor brasileño en que "sólo reconstruyendo el pasado podremos verdaderamente construir el futuro", pero también en que "la Historia no ha acabado, sino que apenas empieza. Y si realmente quisiéramos transformarla en perspectivas de verdadera esperanza es a nosotros a los que, de aquí en adelante, nos cabe hacer la Historia". 